\title{
8
}

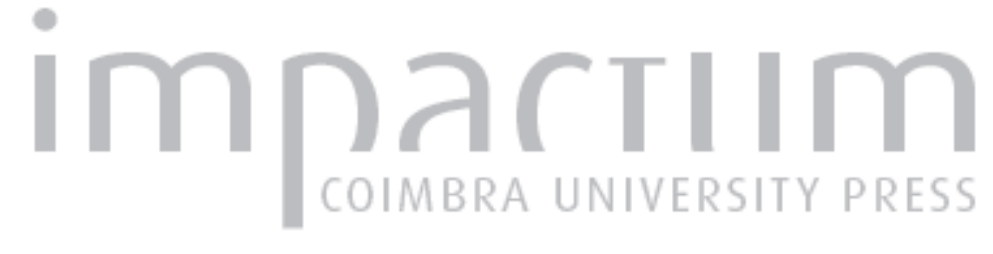

\section{Serão as humanidades incertas e inúteis?: uma leitura filosófica da sua pertinência atual}

Autor(es): $\quad$ Portocarrero, Maria Luísa

Publicado por: Imprensa da Universidade de Coimbra

URL persistente:

URI:http://hdl.handle.net/10316.2/42830

DOI:

DOI:http://dx.doi.org/10.14195/0872-0851_48_7

Accessed : $\quad$ 26-Apr-2023 14:06:27

A navegação consulta e descarregamento dos títulos inseridos nas Bibliotecas Digitais UC Digitalis, UC Pombalina e UC Impactum, pressupõem a aceitação plena e sem reservas dos Termos e Condições de Uso destas Bibliotecas Digitais, disponíveis em https://digitalis.uc.pt/pt-pt/termos.

Conforme exposto nos referidos Termos e Condições de Uso, o descarregamento de títulos de acesso restrito requer uma licença válida de autorização devendo o utilizador aceder ao(s) documento(s) a partir de um endereço de IP da instituição detentora da supramencionada licença.

Ao utilizador é apenas permitido o descarregamento para uso pessoal, pelo que o emprego do(s) título(s) descarregado(s) para outro fim, designadamente comercial, carece de autorização do respetivo autor ou editor da obra.

Na medida em que todas as obras da UC Digitalis se encontram protegidas pelo Código do Direito de Autor e Direitos Conexos e demais legislação aplicável, toda a cópia, parcial ou total, deste documento, nos casos em que é legalmente admitida, deverá conter ou fazer-se acompanhar por este aviso.

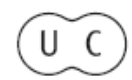




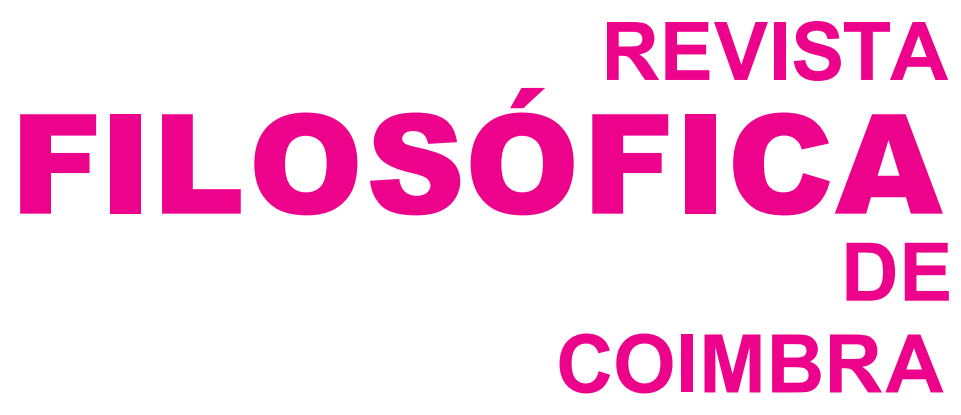

vol. 24 - número 48 - outubro 2015

vol. 24 - número 48 - outubro 2015

Fundação Eng. António de Almeida

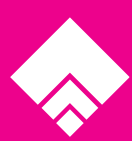




\title{
SERÃO AS HUMANIDADES INCERTAS E INÚTEIS? UMA LEITURA FILOSÓFICA DA SUA PERTINÊNCIA ATUAL
}

\author{
MARIA LUÍSA PORTOCARRERO*
}

Resumo: Este artigo procura defender a natureza e importância das humanidades no mundo contemporâneo, refletindo sobre a sua fundação onto-antropológica e relacionando-as com o fenómeno do humanismo, hoje tão contestado por determinados setores como antropocentrismo. Medita ainda sobre a relevância da temática das humanidades médicas e sobre o papel fundamental das humanidades na compreensão e comunicação da ciência.

Palavras-chave: Humanidades, humanismo, reconhecimento, humanidades médicas, formação narrativa, tradução, comunicação.

Abstract: This paper seeks to defend the nature and importance of the humanities in the contemporary world, reflecting on its onto-anthropological foundation and relating them to the phenomenon of humanism, so criticized, nowadays, as an anthropocentrism. Then, it meditates with much specificity on the contemporary example of medical humanities and on the key role of humanities on science understanding and communication.

Key words: Humanities, humanism, recognition , medical humanities, narrative training, translation, communication

\section{I - Humanidades e humanismos}

É no conceito de pessoa que se centra a problemática das Humanidades e que se concentram nos dias de hoje grandes tensões e conflitos, nomeada-

* Professora Catedrática do Departamento de Filosofia, Comunicação e Informação da Faculdade de Letras da Universidade de Coimbra; email: mlp600@gmail.com 
mente, aqueles que são suscitados pelo desenvolvimento da tecnociência, pelas teorias que proclamam o fim do homem e do humanismo, pela atual programação de um pós- humano e por uma economia de mercado que parece reduzir o homem a material supérfluo. Claro que faz parte da humanidade desenvolver-se na natureza como um ser artificial, isto é, criando um conjunto de relações facilitadas porque mediadas por um sistema de utensílios que é continuamente renovado pelo conhecimento científico e tecnológico.

Podemos mesmo dizer que hoje quase toda a nossa maneira de viver está condicionada por esta mediação científica e tecnológica, que determina a maior parte da nossa maneira de ver, de sentir, de pensar, enfim, de ser. «Conhecemos», «sabemos» e «vemos» — pelo menos do ponto de vista científico - muito mais do que se poderia imaginar noutros tempos sobre o universo e nós mesmos - principalmente no que respeita à nossa dimensão física, biológica (genética). Desenvolvemos também uma quantidade prodigiosa de recursos técnicos capazes de transformarem radicalmente o nosso ambiente e o nosso corpo, chegando até à possibilidade de dispor, de algum modo, da vida.

Por outro lado, e de forma paradoxal, tomámos já consciência de que somos perigosos para nós mesmos e para a natureza, de que gerámos uma grave situação de crise ambiental, à qual corresponde ainda uma outra crise, não menos dramática e que diz respeito ao modo como esquecemos como menos importante o significado da vida humana na sua dimensão ética e cultural. A invasão pela técnica do mundo da vida e das relações humanas, acontecida no séc. XX, deu origem a uma série de patologias que conhecemos bem e que estão associadas à desumanização: a solidão, a depressão, o pânico e o desespero.

Mas, acreditamos que é justamente diante das experiências de crise e de ameaça da dignidade humana que tomamos consciência do seu valor inalienável e do que possa ser afinal o rosto de um humanismo para os nossos dias. É este humanismo o verdadeiro fundamento das humanidades, um humanismo claramente diferente daquele que já M. Heidegger denunciava na sua «Carta sobre o humanismo», como um caminho para o império absoluto da subjetividade e do antropocentrismo. Que humanismo era este afinal? Um humanismo de índole substancialista e metafísica que governou o Ocidente, desde a Modernidade e que veio a ser criticado pelo conjunto das filosofias da suspeita.

Vivemos ainda nos dias de hoje este ambiente de suspeita e de desumanização resultante das confusões a que nos conduziu no Ocidente o antropocentrismo pós-nominalista. O Niilismo, a Desconstrução, o Biologismo genético, o pós-humanismo tão anunciado, são exemplos deste horizonte confuso da crise de sentido que hoje nos assola e nos faz pensar. 
Ordenemo-nos então: o humanismo tem uma raiz europeia, de índole judaico-cristã; enquanto forma de pensar, surge com o mundo romano e tem como característica principal o reconhecimento da humanidade do homem e a recusa da barbárie. "A humanitas de Roma inspirada pela paideia do helenismo tardio das escolas filosóficas, impunha a renúncia à violência e à destruição da cultura. A educação do homem e do cidadão devia realizar-se em benefício da construção da razão e da edificação da paz» ${ }^{1}$. Por outro lado, lembra J.F. Mattei, o humanismo inscreveu-se no movimento de ideias a que o Renascimento chamou studia humanitatis ${ }^{2}$, fenómeno que aconteceu apenas na Europa depois do nominalismo e referiu «o trabalho de erudição presente nas humanidades». Então se o termo humanidades deriva longinquamente da humanitas latina de Cícero e Quintiliano que, segundo Delumeau (1984), se identificava com a polidez de costumes e, mais especificamente, com a civilização, é no Renascimento que ele se impõe.Com efeito quando os intelectuais italianos, a partir de Petrarca, se voltaram para os grandes escritores da Antiguidade, fizeram-no no intuito de recuperar os valores da cultura que aqueles tinham exaltado. Estes intelectuais, a princípio estudiosos das línguas antigas - grego e hebraico, principalmente - começaram a ser identificados como humanistas. Muito rapidamente, entretanto, o humanismo $o^{3}$ passou a ser identificado com uma linha de pensamento determinada: o surgimento de uma nova escola filosófica, que logo se diversificou e passou a caracterizar uma forma de pensamento que cultivou as letras e sobretudo a formação como capacidade de elevação do homem acima da sua particularidade.

A formação, categoria central do Humanismo, determinada mais tarde por Herder como elevação até à humanidade, implicava o trabalho sobre a coisa e, ao mesmo tempo, o trabalho sobre si próprio do homem que assim evitava a pura impulsividade da satisfação imediata das suas necessidades. Desejo inibido, este trabalho implica simultaneamente o distanciamento do imediato da necessidade pessoal e do interesse privado. O que quer dizer que o ponto de vista do outro, que também deseja, é imediatamente reconhecido, como existente, no longo caminho de subida dos homens até ao sensus comunis que permite o reconhecimento. A formação é então uma capacidade de aperfeiçoamento e o caminho do reconhecimento do outro; neste sentido,

1 J.F MATTEI, L'homme dévasté, (Paris:2015), p.55.

2 J.F. MATTEI , L'homme dévasté, p.55.

3 J.F. MATTEI, L'homme dévasté, p.32: «Foi o filósofo alemão Arnold Ruge que o criou o termo humanismus para designar a sua conceção de um «humanismo integral» que e opôs ao 'humanismo unilateral dos socialistas». O termo humanismo apareceu apenas no séc. XIX e não referia a corrente do Renascimento que reabilitou o gosto pelas obras antigas. 
ela apresenta uma estreita relação com o conceito de cultura. No entanto, H-. G. Gadamer lembra-nos que com esta associação nos referimos mais ao resultado da formação do que ao próprio processo da formação, que é aqui o mais importante. A formação deve antes ser entendida como processo e não tanto como resultado, na medida em que o fruto da formação não se realiza segundo o modelo de produção dos objetos técnicos mas nasce do processo interno de formação e configuração de si e por isso encontra-se em constante desenvolvimento e progressão ${ }^{4}$. O conceito de formação, lembra o filósofo, é genuinamente histórico e nada desaparece na formação adquirida, pelo contrário tudo o que se assimila acaba por modificar a pessoa e fazê-la desabrochar.

É justamente o caráter histórico da «preservação» o que importa para uma compreensão das humanidades: «Na formação que foi alcançada nada desaparece, pelo contrário, tudo se guarda. Formação é um conceito genuinamente histórico e trata-se justamente deste caráter histórico da 'conservação' na compreensão das ciências do espírito» ${ }^{5}$. A formação refere pois, segundo Gadamer, que valoriza sobretudo a forma como Hegel a definiu, um movimento de reconhecimento do próprio no estranho, um voltar a si a partir do outro. Neste sentido, lembra Verdade e método, o indivíduo encontra-se constantemente no caminho da formação e da superação da sua naturalidade, uma vez que o mundo em que vai entrando está humanamente mediado ou conformado através da linguagem e dos costumes ${ }^{6}$. Enquanto a formação é o elemento no interior do qual aquele que é formado se move, ela implica justamente aquilo que Helmholtz chamava o tato, isto é, uma sensibilidade e capacidade de sentir situações diferentes da sua e de se colocar nelas, capacidade que não possui quaisquer princípios universais para se poder exercer, nem qualquer conhecimento sedimentado em que possa basear-se ${ }^{7}$. Neste sentido, o tato não pode fixar-se definitivamente e não está expressado. É da própria situação concreta que o tato retira o conhecimento para a resolver. A pessoa formada tem tato, o que a ajuda a manter a distância, a evitar o chocante, a aproximação excessiva e a violação da esfera íntima da pessoa ${ }^{8}$. Ela sabe ver-se a si mesma e aos seus objetivos privados com distância, isto é, como os vêm os demais. Os pontos de vista gerais aos quais se mantém aberta a pessoa formada não representam um padrão fixo de validade mas, pelo contrário, são atuais na medida em que representam os pontos de vista pos-

4 H-G.GADAMER, Gesammelte Werke. Hermeneutik I. Wahrheit und Methode, Grundzüge einer philosophischen Hermeneutik, (Tubingen:1986), p.17 .

5 H.G.GADAMER, Wahrheit und Methode, pp.17-18.

6 H-G.GADAMER, Wahrheit und Methode, p.20.

7 H-G.GADAMER, Wahrheit und Methode, p.22.

8 H-G.GADAMER, Wahrheit und Methode, p .22. 
síveis de outros ${ }^{9}$. Assim Gadamer considera que as ciências humanas que, no séc. XIX adotaram um modelo metodológico semelhante ao do método científico, equivocaram-se pois esqueceram a herança do humanismo e dos seus conceitos fundamentais. Elas compreendem-se muito melhor a partir da tradição humanista do conceito de formação, ainda que não o reconheçam ${ }^{10}$.

Toda a polémica do filósofo com a hermenêutica das ciências humanas, proveniente de W. Dilthey, vai neste sentido. Ao perguntar que forma de conhecimento se pode aprender com a tradição humanista, em ordem a conceber o núcleo das humanidades, o filósofo recorre a Vico e à sua obra De nostri temporis studiorum ratione, sublinhando o valor de toda a tradição que se desenvolveu a partir da retórica como possibilitadora de conhecimento. Vico defende o humanismo contra a formação metódica de Descartes e fala numa nova ciência que tem o seu fundamento em velhas verdades: «refere-se por isso ao sensus communis, ao sentido comunitário e ao ideal humanístico da eloquência, momentos que aparecem já no antigo conceito de sábio»» ${ }^{11}$.

Ao entrar em altercação com as ciências modernas, Vico, explica Gatamar, visa apenas chamar a atenção para os limites de uma metodologia puramente matemática e proclama o cultivo da prudentia e da eloquentia. O que segundo este filósofo dá uma diretriz à vontade humana não é a razão abstrata, mas pelo contrário, a universalidade concreta representada pela comunidade de um grupo, de um povo, de uma nação ou do género humano no seu conjunto. O sensus communis, conceito romano que Vico reabilita e assim defende, recolhe ainda a antiga polémica de Aristóteles contra o saber puramente teórico e a sua defesa da phronésis, como uma outra forma de saber do universal que sabe dirigir-se à situação concreta e suas circunstâncias.

A phrónesis ou sabedoria prática de cariz ético é uma virtude espiritual e nela a determinação do concreto pelo universal é uma particularidade do ser moral; então acolher e dominar eticamente uma situação concreta requer que se subsuma o dado sob o universal, isto é, sob o objetivo que se persegue: pretende-se que surja o correto. No entanto, este universal refere-se a um sentido adquirido pela experiência vivida em comunidade. Assim Vico mostrava que a formação pelo sensus communis não se nutre do verdadeiro matemático mas antes do verosímil ${ }^{12}$. É num tom crítico, orientado contra a especulação nascente dos filósofos modernos, que Vico se insurge e fala no sensus communis. «Sensus communis não significa, neste caso, evidentemente só uma certa capacidade geral de todos os homens, mas ao mesmo tempo

\footnotetext{
9 H-G.GADAMER Wahrheit und Methode, 23.

10 H-G.GADAMER Wahrheit und Methode, p.23.

11 H-G.GADAMER Wahrheit und Methode, p.25.

12 H-G.GADAMER Wahrheit und Methode, pp.26-27.
} 
o sentido que funda a comunidade» ${ }^{13}$. Assim considera Gadamer que devemos, sem dúvida, fundamentar a forma de trabalhar das ciências humanas neste conceito de sensus communis: "Pois o seu objeto, a existência moral e histórica do homem, tal como se configura nos seus factos e obras, está por sua vez decisivamente determinada pelo mesmo sensus communis» ${ }^{14}$, e pela capacidade de juízo.

Esta não pode ensinar-se de acordo com princípios gerais mas apenas exercer-se em cada momento em que é solicitada. O decisivo, lembra-nos Gadamer, não é aqui a aplicação de uma universalidade mas a congruência interna ${ }^{15}$ : quem possui juízo são, não é apenas capaz de julgar o particular a partir de pontos de vista gerais, mas como nos diz Gadamer, "sabe o que é realmente importante, isto é foca as coisas pela ótica dos pontos de vista corretos, justos e sãos» ${ }^{16}$. O juízo funda-se aqui no gosto pelo que é comum, isto é, na forma de conhecer que sabe distanciar-se de si mesmo e das suas perspetivas privadas. O gosto, um conceito de origem mais moral do que estética ${ }^{17}$, refere um fenómeno social de primeiro nível: a aplicação dos costumes, que nunca nos são dados como um todo ou entendidos normativamente, de maneira unívoca, mas precisam de um juízo hermenêutico para avaliar os casos concretos de forma correta. $\mathrm{O}$ gosto carateriza-se pelo facto de a sua escolha conseguir distanciar-se das coisas que fazem parte das necessidades mais urgentes da vida; neste sentido, B. Gracián, que está na origem deste conceito, considerava- o como uma primeira espiritualização da animalidade ${ }^{18}$.

Mas o gosto, como capacidade de distanciamento dos interesses básicos, não se reduz a pura qualidade privada, é pelo contrário bom gosto que se sente ferido pelo que repugna: «O bom gosto é uma sensibilidade que evita de modo tão natural o chocante que o seu modo de agir resulta completamente incompreensível para aquele que não o tem» ${ }^{19}$. Neste sentido, Gadamer lembra como o gosto marca o fenómeno da moda e surge também no âmbito jurídico. Vejamos então: do fenómeno da moda faz parte a universalidade empírica, isto é, a comparação e uma atenção aos demais. Daí que Kant considerasse que era melhor ser um louco da moda do que estar contra a ela ${ }^{20}$.

\footnotetext{
13 H-G.GADAMER, Wahrheit und Methode, p. 26.

14 H-G.GADAMER, Wahrheit und Methode, p.28.

15 H-G.GADAMER, Wahrheit und Methode, p.37.

16 H-G.GADAMER, Wahrheit und Methode, p.37.

17 H-G.GADAMER, Wahrheit und Methode, p. 47.

18 H-G.GADAMER, Wahrheit und Methode, pp. 40-41.

19 H-G.GADAMER, Wahrheit und Methode, p. 42.

20 H-G.GADAMER, Wahrheit und Methode, p. 42-43.
} 
O fenómeno do gosto deve poder caracterizar-se como capacidade de discernimento espiritual, diz Gadamer ${ }^{21}$. «Tanto o gosto como a capacidade de juízo são maneiras de julgar o individual por referência a um todo, de avaliar se ele concorda com tudo o resto, isto é, se é adequado».22

Mas não é apenas na moda que se pratica o sentido do gosto; ele exerce-se também ao nível jurídico. Com efeito, o juiz que aplica a lei não a aplica apenas hic et nunc, mas colabora no próprio desenvolvimento do direito, através da sua sentença. Deste modo, o direito e os costumes aperfeiçoam-se por força da produtividade da sua aplicação a cada caso particular e a capacidade de juízo humana mostra como este tipo de situações completa a amplitude do próprio Direito. Consequentemente o gosto é também uma forma de conhecimento, apesar de não poder tornar-se independente do aspeto concreto em que se realiza nem de poder reduzir-se a conceitos e regras. Neste sentido Gadamer reaviva-nos a memória dizendo: «A aparição do conceito de gosto no séc. XVII, cuja função social e vinculadora, mencionámos, entra assim numa linha da filosofia moral que pode perseguir-se até à antiguidade» ${ }^{23}$.

Este sentido profundamente ético, social e mesmo político do senso comum, da capacidade de juízo e do gosto, cultivados pelo humanismo, perde-se com o avanço da Modernidade, que dá a plena soberania ao sujeito isolado, enquanto fundamento gnosiológico de todo o sentido. Nomeadamente, Kant ao «desacreditar qualquer outro conhecimento teórico que não seja o da ciência natural obrigou a reflexão sobre si das ciências do espírito a apoiarem-se na teoria do método das ciências naturais» ${ }^{24}$.

Foi este tipo de desenvolvimento que veio a possibilitar uma interpretação puramente técnica do pensar, isto é, um pensamento pensado à medida do fazer e do produzir, um ordenamento pragmático dos céus, do mundo e das coisas fez explodir o narcisismo humano. Hoje, este pensamento chegou ao seu ponto limite, é contestado por muitos sectores do pensamento contemporâneo e, de facto, acabou por transformar o próprio homem em mero produto de mercado e puro objeto científico. Tal foi o efeito da moderna vontade de dominar a natureza e o próprio homem: uma redução deste a corpo objeto (res cogitans), manipulável de facto e de direito. Assim se esqueceu o corpo relacional vivido, feito de pó e de barro e habitado pela força de uma vontade, capaz de mover um involuntário, cuja seiva sabe transformar em motivo, projeto e decisão. E cuja temporalidade exige a sua inscrição numa simbólica relacional não metafísica, mas dita pelo sentido comum, que tem na temática das humanidades um papel fundamental.

\footnotetext{
21 H-G.GADAMER, Wahrheit und Methode,p. 43

22 H-G.GADAMER, Wahrheit und Methode, p. 43.

23 H-G.GADAMER, Wahrheit und Methode, p. 45.

24 H-G.GADAMER, Wahrheit und Methode, p. 47
} 
Com este esquecimento da Modernidade se conseguiu um humanismo antropocêntrico, o todo-poderoso narcisismo do sujeito que, diante do vazio que fora aberto pelo nominalismo, consagrou o poder absoluto da razão operatória sobre o mundo, isto é, explorou fundamentalmente a exigência natural do homem para ter e poder. Esqueceu-se com isto o sentimento antropológico fundamental do valer que, como o ter e o poder, constitui o humano na sua exigência relacional de ser.

Hoje sabemos, dados os desenvolvimentos da psicologia e da fenomenologia dos sentimentos fundamentais do homem concreto, que este não é apenas a razão operatória desenvolvida pela modernidade, mas o thumos de que falava já Platão e que são três os sentimentos fundamentalmente inter-humanos, sociais e culturais que não podemos esquecer numa antropologia do homem concreto. São eles: o ter, o poder e o valer. Expliquemos então: segundo P. Ricoeur, que realiza contra a depreciação do sentimento, feita pela antropologia dualista tradicional, uma fenomenologia do homem integral, a constituição do si mesmo, que cada um de nós é, não se esgota de modo nenhum numa técnica ou numa política. Realiza-se na área da cultura ou âmbito do valer que é o fundamento das humanidades. É, de facto aqui que cumprimos o nosso desejo fundamental de ser estimado e reconhecido como pessoa. Por outras palavras, o sentimento de estima de si, que todos nós partilhamos, que nos distingue dos animais, e que se caracteriza por reconhecermos em nós uma capacidade de agir não manietadas por causas físicas, precisa sempre de ser reconhecido pelos outros.

Este desejo de reconhecimento é matricial, mostra-nos P. Ricoeur, dado que para o ser humano a sua existência é sempre e tributária da constituição do seu si próprio por meio do outro. Isto é, o meu sentimento de mim mesmo é sempre recebido a partir da opinião do outro que o consagra. Ora, esta constituição dos sujeitos, esta formação mútua pela opinião do outro, é sempre frágil e consequentemente guiada por mediações ou figuras que não são as que caracterizam a esfera do ter, nem correspondem à esfera das instituições que caracterizam o poder. Devem, pelo contrário, ser procuradas nas obras e nos monumentos do direito da arte da literatura, da filosofia, isto é, naquele tipo de bens que já Platão caracterizava como os alimentos do espírito, o belo por oposição ao útil (Kalón), e que se distinguiam pelo facto de serem completamente diferentes de todos os outros bens.

Porquê? Porque não se reduzem mediante a participação e portando não são codificados como todos os outros. Pelo contrário, ganham com a participação. Assistimos assim dizia-nos já Gadamer, ao nascimento do conceito de razão: quanto mais algo se apresenta para todos convincentemente como desejável, tanto mais os homens têm liberdade, no sentido positivo, isto é, uma verdadeira identidade com o que é comum ${ }^{25}$. Surge deste modo, a origem

25 H.G- GADAMER, A razão na época da ciência, trad. (Rio de Janeiro : 1983), p.48. 
da razão ou o lugar verdadeiro do simbólico dirá depois Ricoeur. O símbolo parece de facto designar o denominador comum de todos os modos humanos de objetivação, isto é, de dar sentido à realidade; o simbólico expressa justamente o caráter não imediato da nossa apreensão do real ${ }^{26}$.

É Ernst Cassirer que, na sua obra Filosofia das formas simbólicas, unifica todas as formas de mediação humana do real sob o título do simbólico. No entanto, P. Ricoeur considera que com esta definição demasiado ampla se dissipa uma distinção fundamental que, a seus olhos, constitui o verdadeiro problema das humanidades: a diferenciação entre expressões unívocas e multívocas. É esta distinção linguística que cria o problema hermenêutico da tradução ou interpretação de que vivem as humanidades. A interpretação, modelo de compreensão e reconhecimento baseado do texto e na sua decifração e não na perceção e sua categorização a partir de categorias prévias do sujeito, refere-se sempre «a uma estrutura intencional de segundo grau que pressupõe que um sentido primeiro é constituído quando algo é visado em primeira mão, mas onde essa mesma coisa remete para outra que é apenas visada por meio dela» ${ }^{27}$.O símbolo define-se, pois, pelo duplo sentido, isto é, por uma estrutura intencional que não consiste na relação direta do sentido à coisa mas na relação do sentido segundo ao sentido primeiro, seja esta relação constituída ou não por uma analogia ou aconteça que o sentido primeiro dissimule ou revele o sentido segundo ${ }^{28}$.

A estrutura de duplo sentido inerente ao discurso das humanidades, mostra-nos P. Ricoeur, não funciona de modo algum sem a interpretação. É assim que o filósofo concede ao conceito de interpretação a mesma extensão que atribui ao símbolo. A interpretação, diz-nos, constitui «o trabalho de pensamento que consiste em decifrar o sentido escondido no sentido aparente, em desenvolver os níveis de significação implicados na significação literal» ${ }^{29}$. É de facto na hermenêutica moderna que se ligam a doação do sentido pelo símbolo e a iniciativa da sua decifração. O objetivo é pensar a partir dos símbolos, de acordo com os símbolos e não por detrás dos símbolos.

São os símbolos e valores que constituem, na verdade, a substância real da vida de um povo: no interior do fenómeno da civilização encontramos de facto, não apenas sistemas de utensílios e instituições, mas «um conjunto de imagens e símbolos por meio dos quais um grupo humano exprime a sua adaptação à realidade, aos outros grupos e à história ( ...). Poderíamos falar neste sentido do núcleo ético-mítico do cerne simultaneamente mo-

26 P.RICOEUR, De l'interprétation. Essai sur Freud (Paris :1965), p.20.

27 P.RICOEUR, De l'interprétation. Essai sur Freud (Paris :1965),p. 21.

28 P.RICOEUR, De l'interprétation. Essai sur Freud (Paris :1965), p.27.

29 P.RICOEUR, Le conflit des interprétations. Essais d 'herméneutique, (Paris: 1969), p.16. 
ral e imaginativo que o poder criador último de um grupo incarna (.....); cada grupo histórico tem neste sentido um ethos, uma singularidade ética que é um poder de criação ligado a uma tradição, a uma memória, a um enraizamento arcaico. É sem dúvida aqui que alcançamos o núcleo concreto da civilização (....); é apenas mediante o conjunto das atitudes concretas modeladas pela imaginação, que valora, que o fenómeno humano se realiza historicamente ${ }^{30}$.

É pois na objetividade dos objetos culturais, lembra Ricoeur, que se realiza a verdadeira prospeção das possibilidades humanas. Daí a importância extraordinária das humanidades. Quando por exemplo V.Gogh pinta uma cadeira, o que ele apresenta é o homem, isto é, projeta uma figura do homem e do seu mundo. Os testemunhos culturais, material das humanidades, fornecem assim a densidade da coisa a estas imagens; fazem-nas existir entre os homens, incarnando-as em obras. É através destas obras, pela mediação destes monumentos que se constitui uma dignidade do homem e uma estima de si. Repitamos então: há na estima de si um desejo de existir que não se realiza pela simples afirmação vital de si mesmo, mas antes pelo jogo de atestação e do testemunho que será interpretado e reconhecido pelos outros. É neste sentido que as humanidades são imbatíveis e de modo algum inúteis: precisamos de testemunhos da nossa capacidade de iniciativa e da reciprocidade do reconhecimento mútuo para passarmos da consciência à consciência de si que nos singulariza enquanto humanidade.

Notemos que apesar de o nosso mundo de hoje quase esquecer o verdadeiro desejo de reconhecimento, esta exigência, lembra-nos Ricoeur, não se satisfaz com relações interpessoais relativas ao ter, pois estas são de exclusão mútua, dão origem ao económico, nem com as de poder que são assimétricas, hierarquizantes e deste modo não recíprocas. A constituição do si mesmo realiza-se, pelo contrário, para além da esfera económica e política na região das relações interpessoais. É aqui que cumpro o desígnio de ser reconhecido e estimado, dado que com efeito, sou o único animal que não quer apenas apoiar o seu eu no meu nem quer apenas dominar para existir.

Pelo contrário quero ser reconhecido no meu valor. A humanidade, hipereconómica e hiperpolítica, do ser humano é representada pelos monumentos culturais que atestam a sua procura de reconhecimento. Compreendemos assim que as obras do espírito (obras de arte, da literatura, de filosofia) não reflitam apenas um meio e uma época mas que projetem possibilidades verdadeiramente humanas de ser no mundo com outros: são objetos que manifestam pela sua universalidade concreta a universalidade abstrata da ideia de humanidade.

30 P.RICOEUR, Lectures, 1. Autour du politique (Paris: 1991),p.246. 
É a variedade dos modos de ser culturais, que refletem diferentes tipos de ação e interação no mundo, que interessam a uma filosofia do reconhecimento, dado que as ocasiões de identificação e de reconhecimento são constituídas pelas variedades de mudança e temporalização. Estas, diz-nos Ricoeur, «apresentam graus de dramatização de acordo com o facto de o reconhecimento passar por graus crescentes de desprezo indo até ao desconhecimento» ${ }^{31}$. As obras culturais, que constituem o material das humanidades, abrem-nos - e só elas o fazem - a situações de perceção e de reconhecimento «nas quais a mudança faz corpo com o tempo que passa» ${ }^{32}$.É nestas circunstâncias que o tempo vivido entra em jogo com o seu aspeto modificador e com a ameaça da morte. Digamos então que reconhecer coisas significa fundamentalmente «identificá-las pelos seus traços genéricos». Quanto às pessoas, em geral elas reconhecem-se pelos seus traços individuais. Traços que são universalizados pela literatura e pela história como universais verosímeis da condição humana.

Exemplifiquemos: os Gregos, por exemplo, que hoje conhecemos pelos testemunhos que lemos, «fazem parte dos nossos antepassados culturais e a imagem que deles fazemos está intimamente ligada à que fazemos de nós ${ }^{33}$. Eles permitem-nos reconhecer o homem como um ser agente, sofredor e capaz, por exemplo, de certas realizações éticas. São para nós exemplo de uma capacidade que temos de reconhecimento de responsabilidade. O mundo homérico, nomeadamente, é revelador de uma capacidade de deliberação que seria mais tarde tratada por Aristóteles e na qual ainda hoje nos reconhecemos. Segundo P. Ricoeur, existe já neste mundo homérico uma apreensão pré-teórica das categorias do agir humano.

É pois a semântica do agir inter-humano que o mundo da literatura, da história, do cinema etc., nos revelam. Nela nos reconhecemos ao reconhecermos valorizações concretas que podem ser apreendidas nas atitudes dos homens relativamente aos outros homens, ao trabalho, ao poder, à guerra, ao amor à experiência da morte ou do sofrimento. Apreendemos deste modo imagens e símbolos por meio dos quais um grupo histórico-cultural representa para si a sua existência, as suas decisões e o seu valor.

Neste sentido já Dilthey dizia que uma grande parte da felicidade humana residia na apreensão e conhecimento de outras épocas e culturas. Podemos aqui falar de uma compreensão do núcleo ético- mítico do centro simultaneamente moral e imaginativo que caracteriza o poder criativo de um grupo e que é capaz de fecundar o nosso. Com efeito, cada grupo histórico tem um ethos próprio, uma singularidade ética que é um poder criativo

31 P. RICOEUR. Parcours de la reconnaissance ( Paris:2004), p. 97.

32 P. RICOEUR. Parcours de la reconnaissance, p.97.

33 P. RICOEUR. Parcours de la reconnaissance, p.111. 
ligado a uma tradição, a uma memória e a um enraizamento arcaico. Cada grupo histórico fala uma linguagem simbólica muito própria que nos revela, como acontece com a diversidade das línguas, que se estas são múltiplas, elas podem sempre comunicar. Podemos sempre traduzir e sentimos mesmo a vontade de traduzir.

Com efeito a vida humana não é apenas constituída por factos e utilidades, mas por sentimentos, valores, símbolos, decisões. O momento crítico em que nos encontramos, hoje marcado, por um lado, pelo paradoxo do desenvolvimento científico-tecnológico e por outro pela crescente desumanização e, consequentemente, pelo grande ceticismo em relação às conquistas e realizações das ciências, apresenta-se então como muito propício para a renovação ou reflexão sobre a importância das humanidades. Com efeito, a tecnicização do conhecimento e, consequentemente da educação, tem fragilizado e comprometido o próprio sistema, isto é, o próprio mercado. Neste sentido, a experiência da cultura mediada pelas artes, pela literatura, pela filosofia permite um outro olhar sobre a realidade, e desencadeia ainda, através do processo de interpretação, um movimento de profunda transformação de si no próprio sujeito que olha, lê e conhece.

Em suma, as humanidades apresentam-se como meio privilegiado de $h u$ manização do ser, na medida em que ampliam as esferas da sua presença, da sua experiência, da sua imaginação e consciência. As humanidades ajudam-nos a sermos mais humanos, propõem-nos universais verosímeis da condição humana que desenvolvem as nossas possibilidades relacionais. Neste sentido se fala hoje da necessidade das humanidades para as formações técnicas, nomeadamente para a medicina.

Com efeito todas estas formações precisam de deliberar e por isso de cultivar uma racionalidade prática que nada tem de simplesmente operatório, mas sim de dialógico e prudencial. Para todas elas o cultivo da imaginação é necessário. Ele permite que a aplicação dos seus saberes passe por um processo hermenêutico de deliberação em que se exerce a capacidade de escuta das situações, o reconhecimento da possibilidade que existe razão fora de nós e a assunção de certos níveis de incerteza. A aplicação retoma então os ensinamentos da capacidade de juízo movida pelo correto e pela congruência.

\section{As ciências e as humanidades: 0 caso das humanidades médicas}

Não foi apenas a Bioética a promotora das humanidades nas ciências médicas, mas a clara consciência das mutações no âmbito da medicina. Os recentes desenvolvimentos tecnológicos e farmacológicos, as profundas transformações no seio dos sistemas de saúde, os novos perfis das profissões 
de saúde dão testemunho disso. A formulação, pelo Hasting Center de Nova York, dos novos fins da medicina, há cerca de vinte anos, muito contribuiu para tal, ao mostrar que a necessidade de questionar os antigos fins da medicina (prolongar a vida, promover e conservar a saúde, aliviar a dor e o sofrimento) resulta não só do facto de esta ciência, ao resolver problemas antigos, ter dado origem a novos, mas sobretudo do facto de não se terem formulado metas e ideais mais adequados. De facto, por isso não ter acontecido os sistemas de assistência médica e sanitária na Europa tem sofrido graves consequências tais como: tornaram-se economicamente insustentáveis; criaram confusões no âmbito clínico; geraram grande frustração social e parecem carecer de um sentido e finalidade coerentes.

Assim como nos é dito na página 54 da versão espanhola do projeto do Hasting Center, «A nova determinação dos fins da medicina deveria ajudar a responder a três perguntas importantes. São elas: quais deverão ser as prioridades da investigação biomédica no futuro? Que implicações têm os fins da medicina no desenho dos sistemas de saúde? Que tipo de formação deverão receber os médicos para cumprir de modo mais satisfatório os novos fins da medicina?» ${ }^{34}$.

O que mudou na medicina contemporânea foi o seu modelo que, de biomédico, isto é, analítico, bioquímico e reducionista, passou a humanitário promovendo a visão bio- psico -social na prática clínica e passando a fomentar a investigação sobre a interação dos fatores sociológicos e psicológicos nas causas e manifestações das doenças. Percebeu-se finalmente que é necessário dar uma maior atenção aos aspetos qualitativos da saúde e da doença, isto é, à forma como os indivíduos interpretam e respondem à doença e à maneira como as sociedades e culturas modelam os significados atribuídos à saúde e doença. Logo, é necessário desenvolver, ao lado da investigação biomédica dominante, a investigação antropológica, sociológica e psicológica. "Aspetos como " a qualidade" na assistência sanitária, as expressões culturais e económicas das necessidades da medicina e a dinâmica da "comunicação" médico-paciente são alguns exemplos do que seriam as linhas de investigação produtivas» ${ }^{35}$.

Reconhece-se pois que, quer no que diz respeito à medicina clínica, quer à saúde pública, é necessário fortalecer a capacidade de investigação em ciências socias, dado que um dos grandes desafios futuros da medicina é o das enfermidades crónicas e, em particular, o da qualidade de vida das pessoas que sofrem. Percebe-se que na sua vertente docente a medicina contemporâ-

34 Hasting Center, Los fines de la medicina. El estabelecimento de unas prioridades nuevas, trad. In Cuadernos de la Fundació Victor Grifols i Lucas, no 11 Barcelona, 2004, p.54

35 Hasting Center, Los fines de la medicina. El estabelecimento de unas prioridades nuevas, p. 56 
nea tem sido dominada, desde há muitas décadas, pelo modelo que é designado como de diagnóstico e tratamento ${ }^{136}$.Quer dizer por um modelo que, mediante o estudo científico da patologia e por meio de uma identificação de relações causais bem fundamentadas, espera encontrar a explicação da doença do paciente e poder extirpá-la. A resposta apropriada da medicina é aqui tecnológica e visa antes de mais poder erradicar a causa da doença.

Este modelo tem no entanto revelado algumas fragilidades, nomeadamente, o facto de investir pouco na prevenção das doenças e na promoção da saúde e o da fragmentação do doente numa coleção de órgãos e sistemas orgânicos. Onde fica então a pessoa no meio disto? Uma educação que promova uma sólida relação médico doente e um conhecimento por parte do futuro médico da complexidade do fenómeno da saúde, da experiência vivida da doença e do mal-estar começa hoje a ser desenvolvida. Procura-se que os médicos recebam uma formação que os torne conscientes dos problemas ocasionados pelas condições psicológicas e sociais em que as pessoas vivem. Condições que desempenham um papel de enorme importância no vivido da doença e na ansiedade que ela pressupõ $\mathrm{e}^{37}$, tal como o frisa relatório sobre Os fins da medicina.

É assim que as humanidades médicas são introduzidas nos curricula de medicina, como acontece desde há uns anos na Suíça. Parte-se do princípio que a tónica colocada no início dos cursos de medicina em bioquímica e fisiologia pode dar aos estudantes a falsa impressão de que é nestas disciplinas e ciências que está o segredo dos objetivos da medicina. O objetivo da introdução das humanidades, nestes curricula, é o de preparar os estudantes para o trato com os pacientes e familiarizá-los com as grandes categorias do mundo vivido. O que finalmente se visa é uma melhor integração na medicina da vertente técnica e humana. São assim promovidos conhecimentos de direito, de ética, de comunicação e filosofia, tal como de antropologia médica e sociologia da medicina. É preciso, sublinha o relatório do Hasting Center, que os novos médicos percebam que o modelo do diagnóstico e tratamento, com a sua tónica no tratamento e na cura, sugere ao médico que o papel da medicina começa apenas quando os pacientes estão doentes e precisam de ajuda. Ora, isto é um erro, pois a prevenção e a promoção da saúde é fundamental.

Além disso o envelhecimento das sociedades é hoje uma realidade inultrapassável logo, é necessário inculcar nos estudantes uma sensibilidade para o problemas das doenças crónicas e neles desenvolver virtudes como a sensibilidade e a comiseração, tal como uma perceção perspicaz e tolerante sobre

${ }^{36}$ Hasting Center, Los fines de la medicina. El estabelecimento de unas prioridades nuevas,p. 64.

37 Hasting Center, Los fines de la medicina. El estabelecimento de unas prioridades nuevas, p. 65 
as incapacidades e incertezas da própria medicina. Sabemos, por exemplo, que os médicos normalmente «não gostam de Geriatria porque não têm as capacidades necessárias para lidar com o 'Caco Velho '(....). 'O Caco Velho' é surdo. `O Caco Velho' é cegueta. A memória do 'Caco Velho` possivelmente está debilitada. (....).Além disso, ele queixa-se de uma série de maleitas há cinquenta anos ou mais. Não vamos conseguir curar nada que uma pessoa tenha há cinquenta anos. Tem a tensão alta. Tem diabetes. Tem artrite. Não há charme nenhum em tratar destas coisas.» «Há todavia uma maneira específica de o fazer, uma metodologia profissional. Podemos não conseguir resolver estes problemas, mas podemos geri-los $\rangle^{38}$.

Neste contexto, as academias suíças das ciências cumprem já o ideal humanista tendo introduzido o projeto «Medical Humanities», consagrado ao ensino de aspetos das ciências humanas e sociais na formação médica ${ }^{39}$. O seu grande objetivo é, através dos conteúdos das humanidades, sensibilizar o futuro médico relativamente ao método e às aproximações da realidade humana vivida da fragilidade e do envelhecimento de modo a que ele possa refletir sobre os valores, atitudes, contextos, culturas que influenciam a saúde e possa corrigir a perceção errada segundo a qual a medicina é uma disciplina puramente científica. Com efeito: «Os profissionais médicos concentram-se em reparar a saúde e não em dar sustento à alma. No entanto - este é o doloroso paradoxo - decidimos que devem ser eles a definir em grande parte como vivemos na nossa etapa final. Há já mais de meio século que tratamos as provações da doença, do envelhecimento e da mortalidade como preocupações médicas. Tem sido uma experiência de engenharia social colocar os nossos destinos nas mãos de pessoas mais valorizadas pela sua proeza técnica do que pela sua compreensão das necessidades humanas» ${ }^{40}$.

Essa experiência, no entanto, falhou, pois o ser humano não vive só de segurança e de destreza técnica. Ele procura, pelo contrário, «uma vida com sentido e valor» ${ }^{41}$ que requer, em caso de doença, não a relação médico doente de tipo paternalista nem a secura eficiente da relação meramente informativa, mas exige «a que é chamada de 'interpretativa" ${ }^{42}$. «Neste caso, o papel do médico é ajudar os doentes a determinarem o que querem» ${ }^{43}$, partilhando com eles as suas decisões.

38 A. GAWANDE, Ser mortal. Nós, a medicina e o que realmente importa no final, trad. ( Lisboa :2014),pp,.49-50.

39 Académies suisses des sciences, Les Medical Humanities en Suisse, Berne, 2012 ( www. akademien -schweiz.ch)

40 A. GAWANDE, Ser mortal, p.132.

41 A. GAWANDE, Ser mortal, p.132.

42 A. GAWANDE, Ser mortal, p.197.

43 A. GAWANDE, Ser mortal, p. 197. 
As Medical Humanities, enquanto ciências culturais da medicina, procuram ajudar os profissionais de saúde a compreender o paciente enquanto outro, no contexto do quadro de referência que é o dele e a reconhecer ainda as variantes culturais e singulares do seu sofrimento. Mas o mais importante é a função crítica que elas revestem relativamente à identidade profissional do cuidador. Isto é, elas promovem o alargamento da sua função imaginativa e desenvolvem a sua capacidade de solicitude ética. Põem ainda em relevo o contexto de sentido em que a medicina age, na maioria das vezes, sem o explicitar. Elas ajudam assim os profissionais do cuidado e aqueles que ainda se estão a formar a encararem-se como operadores culturais, chamados a trabalhar num contexto que é simultaneamente «cultural»e «natural». ${ }^{44}$

A tónica é então colocada nas histórias, narrativas e metáforas que alargam a função imaginativa do pensar e permitem que o profissional conheça o sofrimento e o cuidar nas suas declinações históricas e culturais. Com efeito, questões como a dor, o sofrimento, a dependência, o envelhecimento e mesmo a cura têm sido tema de grandes narrativas que ajudam os homens a compreender os seus contornos difusos e a pôr-se no lugar do outro. A vida humana, tal como a doença, é biológica e biográfica e a narração é a sua tessitura. A narrativa distingue-se da descrição, por poder acolher a complexidade da vida e a temporalidade da experiência vivida; consegue, por meio do seu muthos, passar das peripécias sem nexo da vida à sua integração no universal verosímil que o conto faz aparecer. A operação de construção da intriga, própria da narrativa, transforma os vários incidentes de uma vida numa história capaz de ser seguida. Estabelecendo um fio condutor entre todos estes fatores a intriga forma uma totalidade que pode ser chamada de concordante discordante. Neste sentido compor uma história é do ponto de vista temporal extrair uma configuração verosímil de uma sucessão. A história contada, dizia-o já Aristóteles na sua Poética, revela aspetos universais da condição humana e por isso o filósofo considerava a Poética mais filosófica do que a história.

Sempre ouvimos dizer e repetir, que a vida humana tem algo a ver com a narrativa, que merece ser contada e que não pode ser reduzida à mera causalidade física ou à linguagem matemática, diz Ricoeur. Aqui está, de facto, o núcleo da humanidade da vida: ela precisa de ser reconhecida, na sua temporalidade e, por isso, de ser contada. De facto, a própria estrutura do agir humano implica toda uma semântica da condição da pluralidade que a distingue muito claramente do mero movimento físico ou do comportamento psicofisiológico. Com base nela, conseguimos perceber o que só para o homem existe, a unidade do acontecimento e do significado, ou por outras palavras, o que sejam os revezes vividos da fortuna, o amor, o ódio, a alegria,

44 Académies Suisses des Sciences. Les Medical Humanities en Suisse,p. 26 
a inveja, a morte etc. Entendemos ainda categorias básicas do agir, como sejam o projeto, a motivação, o objetivo, as condições e circunstâncias do decidir. Podemos assim afirmar, com P. Ricoeur, que a nossa familiaridade com a rede conceptual da ação, se deve à familiaridade que temos com as histórias de vida que lemos, com os enredos que recebemos, por meio da narrativa histórica e de ficção. A empírica do viver quotidiano, marcada pelo primado do agir e do padecer, da relação e da interação, di-la a narrativa por meio de um muthos que, ordenando poeticamente factos dispersos da condição humana, cria uma mimese, capaz de enriquecer a imaginação e assim conduzir à apreensão dos universais poéticos que governam o agir e as peripécias da condição humana. A narrativa gera assim uma forma de compreensão que está muito mais próxima da sabedoria prática e do juízo moral do que da ciência teorética. É capaz de propor à imaginação e à sua mediação do real várias figuras que constituem experiências de pensamento pelas quais aprendemos a encadear aspetos éticos da conduta humana. Pelas significações poéticas aprendemos então como os revezes de fortuna resultam desta ou de aquela conduta e isto é construído pela intriga narrativa. É devido à familiaridade que temos com os tipos de intriga recebidos na nossa cultura que aprendemos a relacionar virtudes ou outras formas de excelência com a felicidade e a infelicidade. Estas lições da poética narrativa constituem os universais poéticos, de que falava já Aristóteles, de grau inferior aos lógico-teoréticos mas absolutamente necessários ao sentido da vida.

É neste tipo de universais verosímeis, tão diferentes dos da ciência e seu princípio de verificabilidade, que habitam as humanidades com a sua categoria fundamental, o reconhecimento. Reconhecimento de si, como um si mesmo, o único animal capaz de se designar a si mesmo, capaz de contar a história da sua vida, capaz de agir e de ser imputável pelos seus atos, capaz de amar, de recordar, de perdoar e de reconhecer o outro no seu valor inalienável. São também estes universais que nos permitem compreender a incapacidade e suas formas, a doença, o envelhecimento, a lenta perda de capacidades e a revolta que muitas vezes ela comporta, como por exemplo acontece em algumas narrativas de Vergílio Ferreira.

Para compreender o sofrimento, que nos atinge, é necessário confessá-lo ou melhor contá-lo, tal foi a lição que aprendemos com P. Ricoeur e sua meditação sobre o mal. Por mais absurda que seja a experiência humana, tocada pelo sofrimento, pela angústia ou pelo pecado, ela exige sempre comunicação, também foi este o grande ensinamento da psicanálise. "Somos narradores por instinto de liberdade porque nos repugna a servidão da própria condição humana num mundo onde não pode haver um sítio próprio para os nossos desejos e as nossas ânsias de verdade, de salvação e de plenitude» ${ }^{45}$.

45 TOMÁS DOMINGO MORATALLA, Bioética y cine. De la narración a la deli- 
A forma de ser que é temporalidade vivida exprime-se pois narrativamente, o que quer dizer, segundo Ricoeur, que o tempo apenas se torna humano quando é articulado narrativamente e que a narrativa é uma forma transcultural de dizer o tempo vivido. Ela é, de facto, um meio fundamental para exprimir a vida vivida, dado que a experiência desta é já em si mesma composta por elementos narrativos. Tal é a tese desenvolvida por P. Ricoeur na sua obra Tempo e narrativa, momento extraordinariamente significativo do seu esforço filosófico para elaborar uma antropologia que se dê conta do que é realmente o homem na sua complexidade inter-relacional.

Para poder dizer a ação, a realidade em ato que acontece entre os homens que agem e a temporalidade vivida deste agir, Ricoeur fundamenta o recurso à narrativa de que já falavam outros filósofos como Ortega y Gasset, W. Schapp e H. Arendt. Fá-lo recorrendo à Poética de Aristóteles e seu núcleo fundamental, a tríade mimesis-muthos-catharsis, e ainda aos ensinamentos da moderna narratologia. Mas para Ricoeur o processo de composição narrativa não está completo no texto, mas apenas no leitor e só sob esta condição torna possível a reconfiguração da vida pela narrativa. Para o filósofo o sentido da narrativa surge na intersecção do mundo do texto e do leitor. $\mathrm{O}$ ato de leitura é o momento fundamental deste processo; é nele que se situa a capacidade da narrativa transfigurar a experiência do leitor. Com efeito, a vida é um fenómeno biológico enquanto não é interpretado; é na interpretação que a ficção histórica e literária desempenham um papel mediador. Para Ricoeur a ficção narrativa em particular é um elemento irredutível da nossa compreensão de nós mesmos. É sempre a mistura de ação e sofrimento, que constitui a verdadeira textura da vida humana, que a narrativa espera imitar de modo criativo; ela parte pois da semântica da ação que marca a vida em relação e dos recursos simbólicos do campo prático que permitem falar mesmo numa qualidade pré-narrativa da experiência humana de sentido. A experiência narrativa é mesmo considerada pelo filósofo como o grande laboratório onde ensaiamos a nossa capacidade de juízo moral ${ }^{46}$.

A ligação entre medicina e narrativa não é bem o escopo fundamental das humanidades médicas suíças, e ela não é nova. Aparece nos anos sessenta do séc. XX nos Estados Unidos e procura compreender o encontro clínico a partir de um desenvolvimento de competências narrativas no prestador de cuidados. O escopo principal é levar médico e doente à construção conjunta de um relato conjunto em que o médico e o paciente desempenham papeis diferentes e por meio do qual o doente consiga reaver a sua autonomia. Pensa-se que se o médico não é capaz de desenvolver estas capacidades, não consegue dar lugar a que o paciente lhe conte toda a sua história e este não

beración, (Madrid :2010), p.53.

46 P.RICOEUR, Soi-même comme un autre (Paris :1990), pp.139-140. 
se sentirá ouvido. Para ajudar os médicos a compreender a experiência da doença grande parte da medicina americana vem dando atenção à competência narrativa que $\mathrm{R}$. Charon define como «o conjunto de habilidades que são exigidas para reconhecer, absorver, interpretar e comover-se com as histórias que se leem e contam ${ }^{47}$. A convicção de fundo é que a leitura da narrativa desenvolve capacidades essenciais para a medicina e que hoje fazem falta nos profissionais: empatia, sensibilidade para as dimensões emocionais e éticas do cuidado, reconhecimento do outro, compromisso ético.

\section{As Humanidades e a linguagem das ciências exatas.}

Além da sua importância crucial para uma formação mais envolvente dos profissionais das ciências exatas, que lidam com a praxis humana, as Humanidades são ainda relevantes, dado que só elas são capazes de estabelecer o papel de mediador ou tradutor da linguagem especializada das várias ciências, que hoje se multiplicam, sem no entanto conseguirem comunicar entre si. Enquanto disciplinas que lidam basicamente com as condições de possibilidade da comunicação e da ação inter-humana é a gramática a retórica, a história e a poética que sobretudo interessam às Humanidades. Elas sabem pois compreender o discurso como a mediação da realidade e como uma transgressão da incomunicabilidade humana. Sabem que, apesar de existirem múltiplas linguagens e abordagens do real, sempre existe a tradução e o que vertemos de uma linguagem para outra é o intencionado do seu discurso, ou seja o caráter propriamente semântico do dito. Ora, «Só o discurso, portador de um intencionado, do sentido e da referência, é possível de transpor de uma língua para a outra e exerce uma função de mediação» ${ }^{48}$. É pois o sentido e a referência do discurso científico que devem ser compreendidos e traduzidos para a linguagem quotidiana, é o seu caráter semântico que deve ser compreendido e tornado comunicável. O discurso científico é, como todo o discurso, uma forma de significar e designar a realidade, a vida e a morte e reclama, por isso, uma interpretação e uma aplicação prática. É preciso compreender a inscrição da ciência no conjunto da cultura, nomeadamente a interferência da sua prática teórica nas práticas, que guiam as nossas vidas, dado que o homem vive justamente no cruzamento das várias práticas: teórica, técnica, moral, jurídica e política.

47 TOMÁS DOMINGO MORATALLA, LYDIA FEITO GRANDE Bioética narrativa ( Madrid:2013), p.102.

48 P. RICOEUR, « Discours et communication», in M.REVAULT D’ALLONES ET F.AZOUVI, L'Herne. Ricoeur, (Paris : 2004), p. 54. 
Assim se impõe a tarefa de tradução da linguagem da ciência de modo a que se perceba que o que deve ser compreendido, nos seus textos, por vezes ininteligíveis, é a sua referência não ostensiva ou o conjunto de propostas de habitar o mundo que elas oferece ao homem. É isto o que deve ser comunicado. É com efeito no âmbito deste tipo de referências invisíveis que se pode estabelecer uma comunicação proveitosa. Questionando as condições de possibilidade do sentido, e refletindo sobre a universalidade da comunicação e da tradução, as humanidades podem pois contribuir para um diálogo frutífero com a linguagem especializada, para não dizer altamente tecnicizada da ciência. Só elas conseguem entender que a ação humana «não é dada simplesmente a ver, como todos os fenómenos deste tipo de natureza da qual ela faz parte; pelo contrário, ela é dada a compreender a partir das expressões que são de cada vez os efeitos e os sinais das intenções que lhes dão sentido e dos atos criadores de sentido que, por vezes, produzem. Daqui resulta que o conhecimento do homem não se joga num plano de exclusividade, o da observação e da explicação; mas desenvolve-se na interface da observação natural e da compreensão reflexiva. O homem «é ao mesmo tempo um ser observável, como todo o ser da natureza, da qual ele é uma parte, e um ser que se interpreta a si mesmo» ${ }^{49}$.

As Humanidades sabem que a ciência dura, sempre mais eficiente na compreensão da arquitetura da matéria, de que somos feitos e as ciências do espírito, sempre mais próximas do vivido, são aproximações diferentes e necessárias da complexidade humana a que chamamos corpo apropriado. A abordagem descritiva da matéria, que nos constitui e que nos desfaz um dia e a compreensão narrativa do tempo vivido que nos cabe, com as suas alegrias, revoltas, sentimentos, violências, arrependimentos e revezes de fortuna, devem poder integrar-se, e só as Humanidades o podem fazer, dada a sua preocupação com o reconhecimento, a comunicabilidade e a tradução.

49 P.RICOEUR, «Que la science s'inscrit dans la culture comme "pratique théorique”» in www.fondsricoeur.fr, articles et textes en ligne, consultado em 3-05-2015. 